Article

\title{
Real-Time Transient Thermal Rating and the Calculation of Risk Level of Transmission Lines
}

\author{
Jiapeng Liu ${ }^{1, *}$, Hao Yang ${ }^{1}$, Shengjie Yu ${ }^{2, *}$, Sen Wang ${ }^{3}$, Yu Shang ${ }^{3}$ and Fan Yang ${ }^{1}$ \\ 1 State Key Laboratory of Power Transmission Equipment \& System Security and New Technology, \\ Chongqing University, Chongqing 400044, China; yanghao@cqu.edu.cn (H.Y.); \\ yangfancqu@gmail.com (F.Y.) \\ 2 Department of Urology, the Second Affiliated Hospital, Chongqing Medical University, \\ Chongqing 400016, China \\ 3 State Grid Shanxi Electric Power Corporation Research Institute, Xi'an 710054, China; \\ luoyangxiyue@163.com (S.W.); Xsy-CQU@outlook.com (Y.S.) \\ * Correspondence: matthew0619@foxmail.com (J.L.); bbyddh@sina.com (S.Y.); Tel.: +86-023-6510-2434 (J.L.)
}

Received: 16 February 2018; Accepted: 30 April 2018; Published: 12 May 2018

Abstract: With the increasing consumption of electric energy, how to improve the capacity of transmission lines within safe margins is an urgent problem to be solved. This paper presents a transient thermal rating method under real-time meteorological conditions. The result of thermal ratings under different conditions shows that this rating approach can significantly increase the capacity of the line. As some of the most critical variables are remaining time and initial temperature, their influence upon the rating is studied. The method of statistical analysis is used to determine the ampacity at different risk levels. The result indicates that with smaller remaining time, the ampacities are larger, and with larger ampacities, the risk of thermal overload is greater. The choice of risk level would heavily affect the values of ampacity.

Keywords: transient thermal rating; overhead transmission line; real-time meteorological conditions; risk level

\section{Introduction}

Over the decades, the contradiction between grid construction and economic development has become increasingly prominent due to the ever increasing consumption of electric energy. A straightforward solution is constructing new transmission lines, but this faces a series of problems, such as large investments and environmental restrictions [1-6]. For example, establishing a new transmission line in Alberta is not only a political, but also a controversial problem [7]. The best way is to make better utilization of the capacity of the line without risking the integrity of the system [8-10]. For now, static thermal rating is used world-wide by many utilities, which considers very conservative meteorological conditions, such as high ambient temperature, high solar radiated heat intensity, low wind speed, and wind is assumed to be perpendicular to the conductor [11,12]. This gives a very conservative result, and a high constraint of the capacity of the line.

Increasing ampacities of overhead transmission lines has long been of interest to engineers. In [13], differences in methods of thermal rating in standard of Institute of Electrical and Electronics Engineers (IEEE) and International Council on Large Electric Systems (CIGRE) [14,15] are compared. In [16], Power Donut 2 is used for accurate prediction of the capacity and to minimize the risk of the line. In [17], a method to assess the reliability of dynamic thermal rating (DTR) systems is proposed. In [18], a novel method to calculate probability density functions of future ampacity based on probabilistic weather forecasts is presented. In [19], a new modelling method for DTR is presented which is superior in terms of both probability distribution and fitting accuracy. In [20], the wind simulations commonly 
employed by the wind energy industry is applied to inform rating estimation during network planning and operation. In [21], the software of Comsol Mutiphysics is used to investigate the impact of the more accurate mixed convective cooling model on overhead line conductors.

In this paper, a real-time transient thermal rating method based on the transient thermal balance is proposed from the perspective of increasing the capacity of the line. In order to verify the increasing effect of the above method, a comparison among thermal ratings under different conditions is made, and the influence of different variables upon transient thermal rating is analyzed. The method of statistical analysis is used to determine the ampacity at different risk levels for assessing the thermal risk of the line, which provides the reference and basis for the operation and scheduling of the line. This method provides a more comprehensive way to explore the available capacity of transmission lines.

\section{Methodology}

The operating temperature of transmission lines is decided by the heat exchange between conductor and environment. The maximum allowable ampacity is the current passing through the overhead transmission lines when the operating temperature of the conductor reaches the maximum allowable value, and the heat exchange between conductor and environment reaches a dynamic balance. Assuming that the overhead transmission line is a uniform conductor, the steady-state thermal balance equation for the conductor in the IEEE Std738 ${ }^{\mathrm{TM}}-2012$ standard [14] is given by

$$
q_{c}+q_{r}=q_{s}+I^{2} \cdot R\left(T_{s}\right)
$$

where $q_{c}$ is convection heat loss rate, $q_{r}$ is radiated heat loss rate, $q_{s}$ is heat gain rate from sun, $I$ is conductor current, and $R\left(T_{s}\right)$ is alternating current $(\mathrm{AC})$ resistance of conductor at temperature $T_{s}$.

For the transient thermal rating, it is up to the maximum allowable operating temperature, which determines the maximum sag and rate of annealing. The transient thermal balance equation for the conductor in the IEEE Std738 ${ }^{\mathrm{TM}}-2012$ standard is given by

$$
\frac{d T_{s}}{d t}=\frac{1}{m \cdot C_{p}}\left[R\left(T_{s}\right) \cdot I^{2}+q_{s}-q_{c}-q_{r}\right]
$$

where $m$ is mass of conductor per unit length, $C_{p}$ is specific heat of the conductor material, $t$ is remaining time.

The total specific heat of the conductor is equal to the sum of the specific heat of the components of the conductor, that is

$$
m \cdot C_{p}=\sum m_{i} \cdot C_{p i} \cdot
$$

For the aluminum conductor steel reinforced (ACSR) conductors, the mass and specific heat of aluminum and steel per unit length are shown in Table 1.

Table 1. Mass $(m)$ and specific heat $\left(C_{p}\right)$ of aluminum and steel per unit length.

\begin{tabular}{ccc}
\hline Material & $\mathbf{m} /\left(\mathbf{k g} \cdot \mathbf{m}^{-\mathbf{1}}\right)$ & $C_{p} /\left(\mathrm{J} \cdot \mathbf{k g}^{\left.-\mathbf{1} \cdot{ }^{\circ} \mathrm{C}\right)}\right.$ \\
\hline Aluminum & 1.116 & 955 \\
Steel & 0.5119 & 476 \\
\hline
\end{tabular}

Assuming that the initial state of transmission lines has reached the steady state, the steady-state thermal balance of the transmission line will be destroyed during the transience when the current passing through the line is suddenly increased. The resistance heat generated by the current and the heat gained from sun is greater than the heat dissipation of the conductor, which causes the temperature of the conductor to increase. The process of temperature increment can be divided into 
many time steps, which is relatively short enough to assume the ambient meteorological conditions remain the same. In each time step, formula (2) can be rewritten as

$$
\Delta T_{s}=\frac{R\left(T_{s}\right) \cdot I^{2}+q_{s}-q_{c}-q_{r}}{m \cdot C_{p}} \cdot \Delta t
$$

where $\Delta T_{s}$ is conductor temperature increment corresponding to time step, where $\Delta t$ is the time step.

From the initial state, the temperature of the conductor in $n+1$ min can be expressed as

$$
T_{n+1}=\Delta T_{s}+T_{n}(n=0,1,2 \ldots),
$$

where $T_{n+1}$ and $T_{n}$ are the temperatures in $n+1$ and $n$ minute respectively; and $T_{0}$ is the initial temperature of the conductor.

The temperature increment of transmission lines under different currents can be tracked by the above formulas. The transient ampacity of transmission lines is the jump current corresponding to the temperature of conductor increasing from the initial state to its maximum allowable value within the remaining time.

Assuming the initial meteorological conditions of the conductor remain unchanged for the rest of the time, the process of transient thermal rating of the transmission line is calculated as shown in Figure 1.

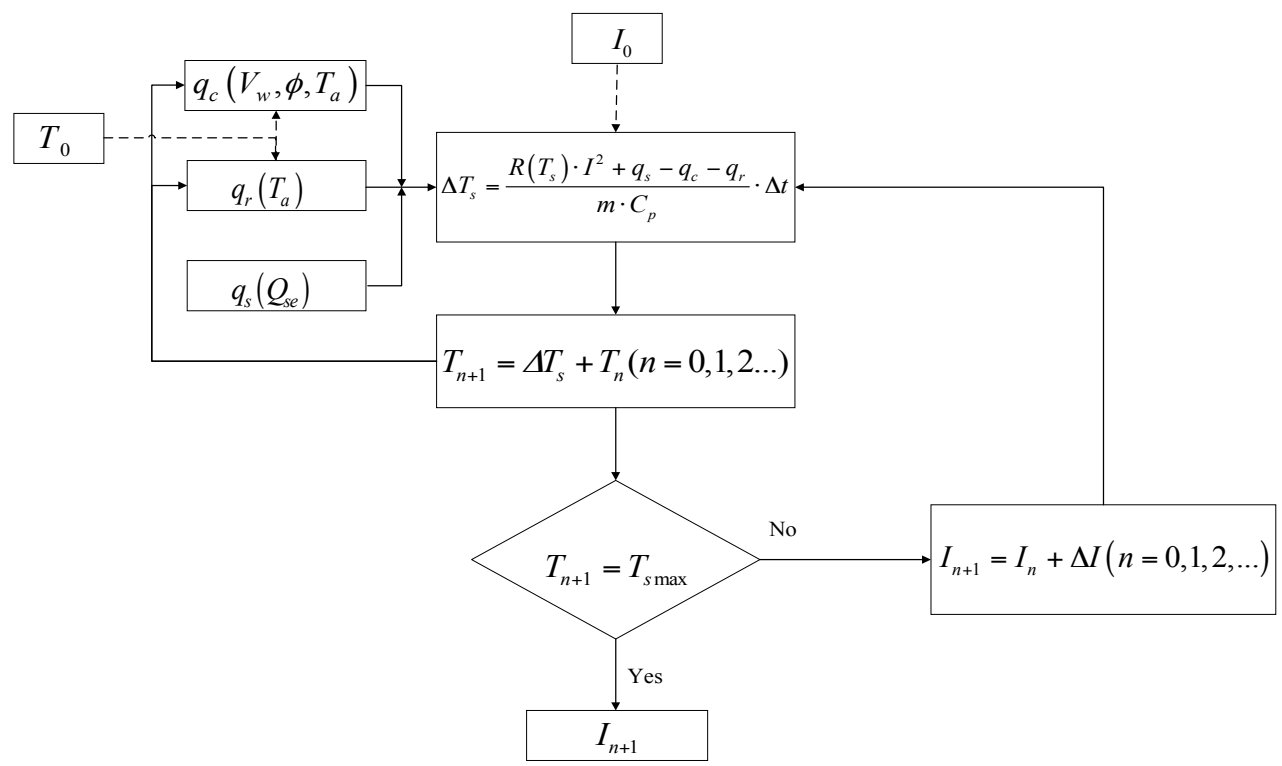

Figure 1. Overview of the process the transient thermal rating method. $T_{0}$ : steady-state temperature; $I_{0}$ : steady-state current; $q_{c}$ : convection heat loss rate; $V w$ : wind speed; $\varphi$ : angle between wind and axis of conductor; $T_{a}$ : ambient temperature; $q_{r}$ : radiated heat loss rate; $q_{s}$ : heat gain rate from sun; $Q_{s e}$ : solar radiated heat intensity; $T_{s}$ : resistance of conductor at temperature; $I$ : conductor current.

The first step is to set the steady-state temperature and current $\left(T_{0}, I_{0}\right)$ of the line as the initial parameters of the transient conditions. The meteorological data, such as wind speed, angle between wind and axis of conductor, ambient temperature, and solar radiated heat intensity $\left(V_{\mathrm{w}}, \varphi, T_{\mathrm{a}}, Q_{\mathrm{se}}\right)$ of the line are used to calculate the temperature increment of every time step. If the accumulation value of temperature at the last time step reaches the maximum allowable value $\left(T_{\mathrm{smax}}\right)$, then $I_{0}$ is the transient ampacity of the line. If not, iterating $I_{0}$ until the temperature meets the requirement. 


\section{Transient Thermal Rating of Overhead Transmission Lines}

\subsection{Case Study}

A $500 \mathrm{kV}$ quad bundle conductor with 7 towers in Zhejiang Province, China, is set as a sample to study the transient thermal rating of the whole year with a time resolution of one hour. Table 2 shows the basic parameters of the line and the real-time meteorological data of tower 1 in 2012 is shown in Figure 2.

Table 2. Basic parameters of the $500 \mathrm{kV}$ quad bundle transmission line.

\begin{tabular}{cc}
\hline Parameters & Value \\
\hline Type of Conductor & LGJ-400/35 \\
$D_{o}{ }^{1} / \mathrm{m}$ & 0.02682 \\
$L a t^{2}{ }^{\circ}$ & $28.454884 \sim 28.464759$ \\
$H_{e}{ }^{3} / m$ & $63 \sim 196$ \\
$\varepsilon^{4}$ & 0.9 \\
$\alpha^{5}$ & 0.9 \\
$Z_{l}{ }^{6} /^{\circ}$ & 45
\end{tabular}

${ }^{1} D_{o}$ is outside diameter of conductor. ${ }^{2}$ Lat is latitude of the line. ${ }^{3} H_{\mathcal{e}}$ is elevation of conductor above sea level. ${ }^{4} \varepsilon$ is emissivity of the conductor. ${ }^{5} \alpha$ is solar absorptivity of the conductor. ${ }^{6} Z_{l}$ is azimuth of the line.
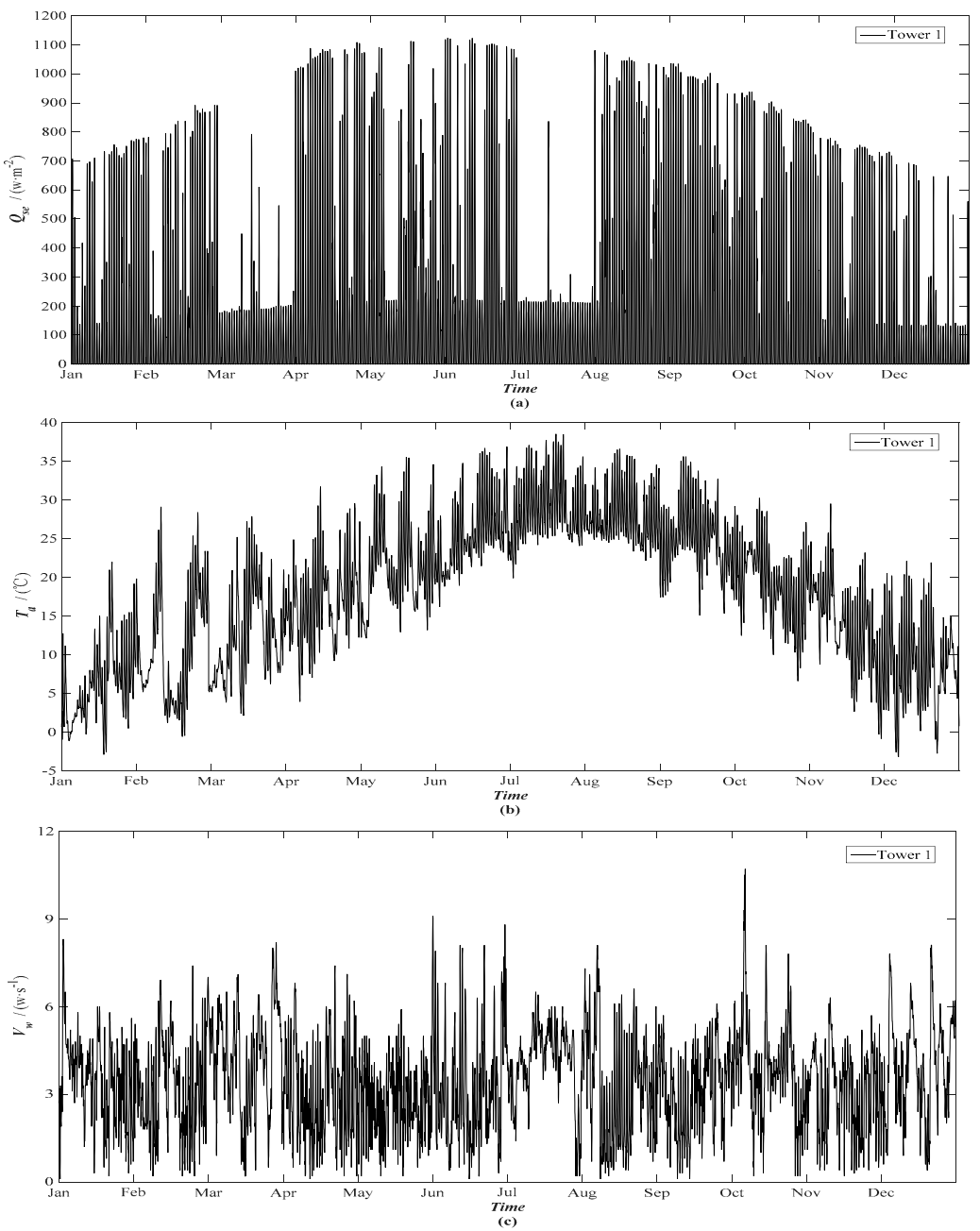

Figure 2. Cont. 


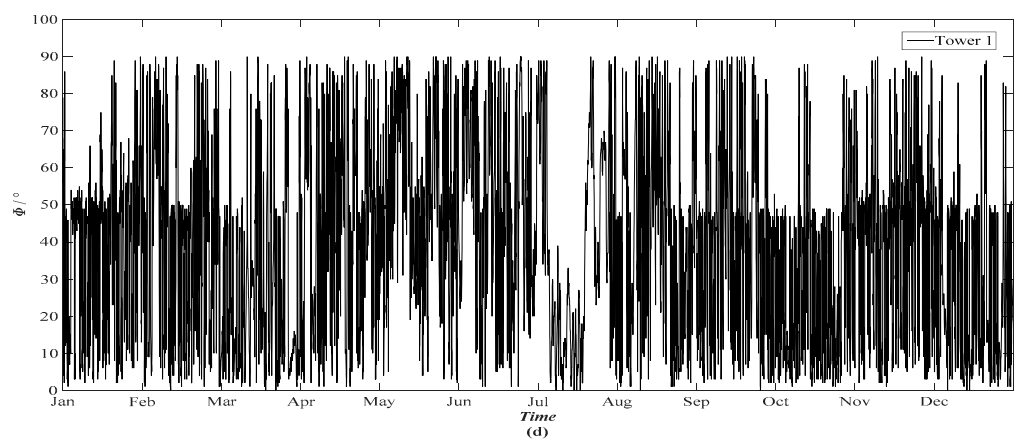

Figure 2. (a) Total solar radiated heat intensity of tower 1 in 2012; (b) ambient temperature of tower 1 in 2012; (c) wind speed at conductor of tower 1 in 2012; (d) angle between wind and axis of conductor of tower 1 in 2012.

The maximum allowable temperature of the overhead transmission line is $70{ }^{\circ} \mathrm{C}$ for normal operation and $80^{\circ} \mathrm{C}$ for transient operation. The calculation parameters of the line is shown in Table 3 .

Table 3. Calculation parameters of the $500 \mathrm{kV}$ quad bundle transmission line.

\begin{tabular}{cccc}
\hline Parameters & $\boldsymbol{T}_{\mathbf{0}} /{ }^{\circ} \mathrm{C}$ & $\Delta \boldsymbol{t} / \mathrm{min}$ & $\boldsymbol{t} / \mathrm{min}$ \\
\hline Value & 25 & 1 & 30 \\
\hline
\end{tabular}

The result of transient thermal rating of 7 towers of the transmission line in 2012 is shown in Figure 3.
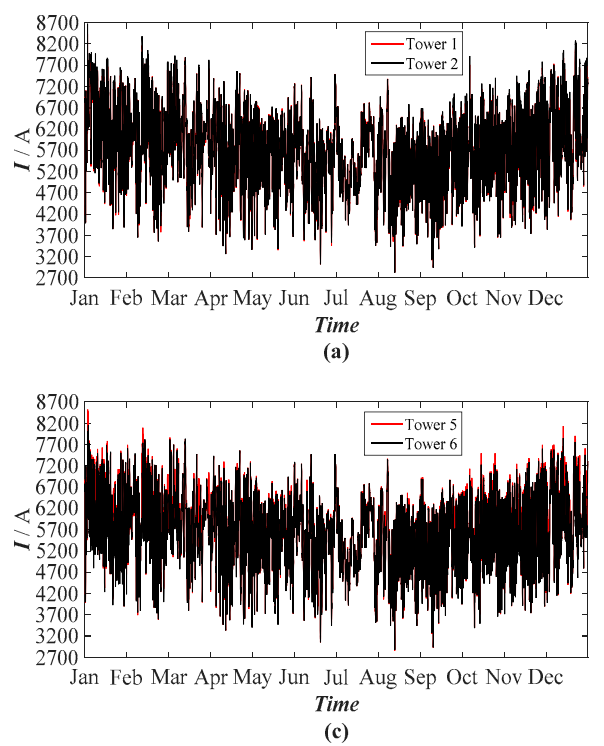

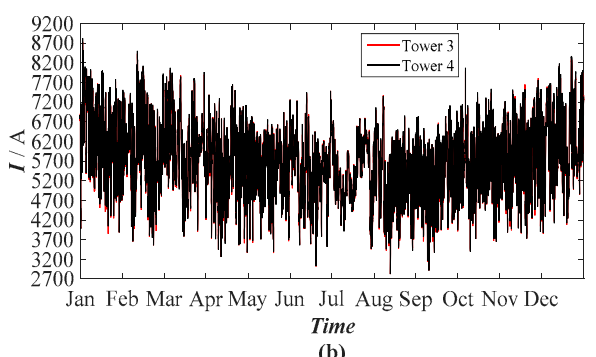

(b)

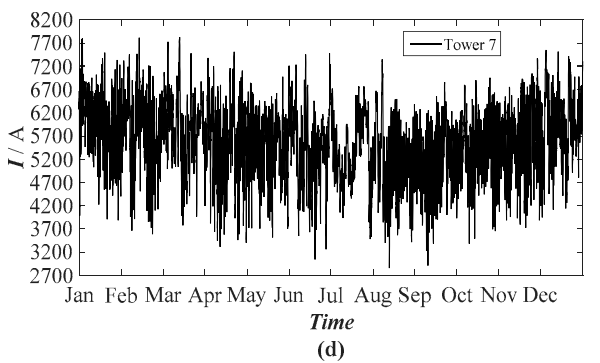

(d)

Figure 3. (a) Transient thermal rating of tower 1 and 2 of the transmission line in 2012; (b) Transient thermal rating of tower 3 and 4 of the transmission line in 2012; (c) Transient thermal rating of tower 5 and 6 of the transmission line in 2012; (d) Transient thermal rating of tower 7 of the transmission line in 2012.

The max thermal rating of a line at each moment is the minimum value of all the towers of the line at that moment, which is

$$
I_{\max }=\min \left(I_{i}\right),
$$

where $I_{i}$ is the current of its $i$ th tower. 
Therefore, the max transient thermal rating of this line in 2012 is shown in Figure 4.

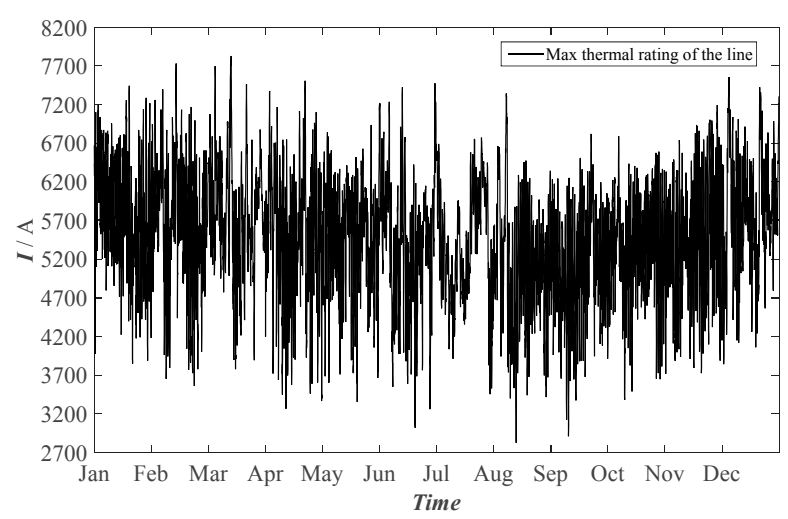

Figure 4. Max transient thermal rating of the transmission line in 2012.

We can see from Figure 4 that the maximum and minimum value of transient thermal rating in the whole year are $7828 \mathrm{~A}$ and $2824 \mathrm{~A}$ respectively, and the difference between them is $5004 \mathrm{~A}$. The main reason that causes the change of transient thermal rating in the whole year is the differences in meteorological conditions. In the summer time, the meteorological conditions are usually harsher than winter, so the values of transient thermal rating in summer are usually lower than winter.

The calculation model can be used to track the temperature increment of the transmission line. Figure 5 shows the temperature increment curve of the transmission line on 30 June 2012 at 12:00, 18:00; and 31 December 2012 at 5:00, 24:00. The values of transient thermal rating at each time are $5236 \mathrm{~A}, 6288 \mathrm{~A}, 5504 \mathrm{~A}$, and $7308 \mathrm{~A}$, respectively.

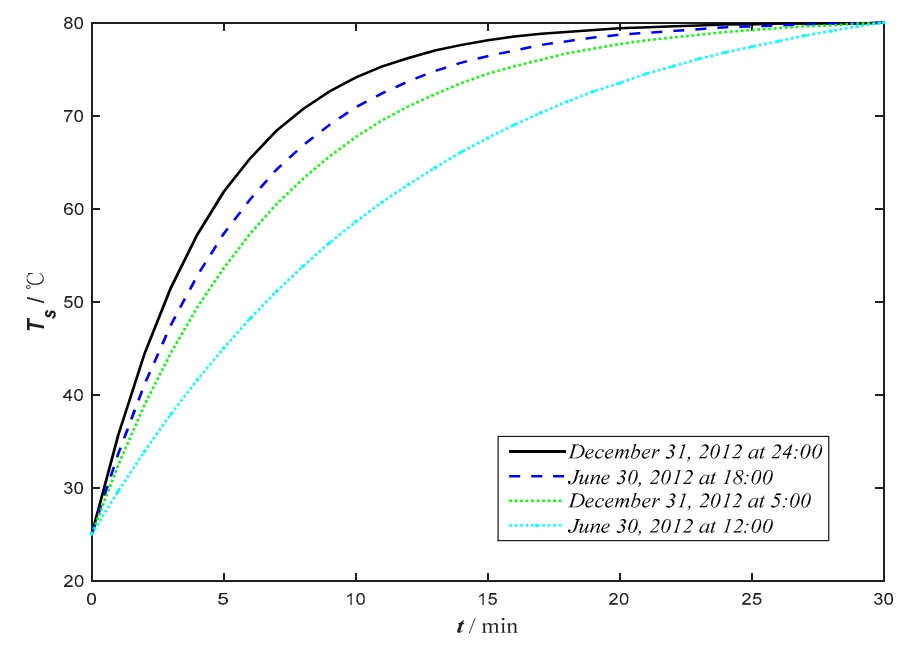

Figure 5. Temperature increment of the transmission line on 30 June 2012 at 12:00, 18:00; and 31 December 2012 at 5:00, 24:00.

From the above figure, one can conclude that with higher ampacity, the conductor takes less time to reach a relatively high temperature. When the temperature rises, approaching the maximum allowable value for transient operation of the line, the temperature increment becomes slower. The reason for that is the heat dissipated by the conductor continues to approach the heat absorbed by the conductor, and the residual heat that makes the temperature rise is continuously decreasing. 


\subsection{Comparison and Analysis under Different Conditions}

In order to verify the increasing effect of transient thermal rating in real-time meteorological conditions, this paper compares it with the thermal ratings of the line in steady-state and static conditions. Steady-state thermal rating is the ampacity of transmission lines under long-term operation, and it does not need to consider the temperature change of transient durations. Static thermal rating means the meteorological conditions are fixed and conservative. Table 4 shows specific values of meteorological conditions in static thermal ratings. Figure 6 shows the comparison of thermal ratings under different conditions.

Table 4. Specific value of meteorological conditions in static thermal rating.

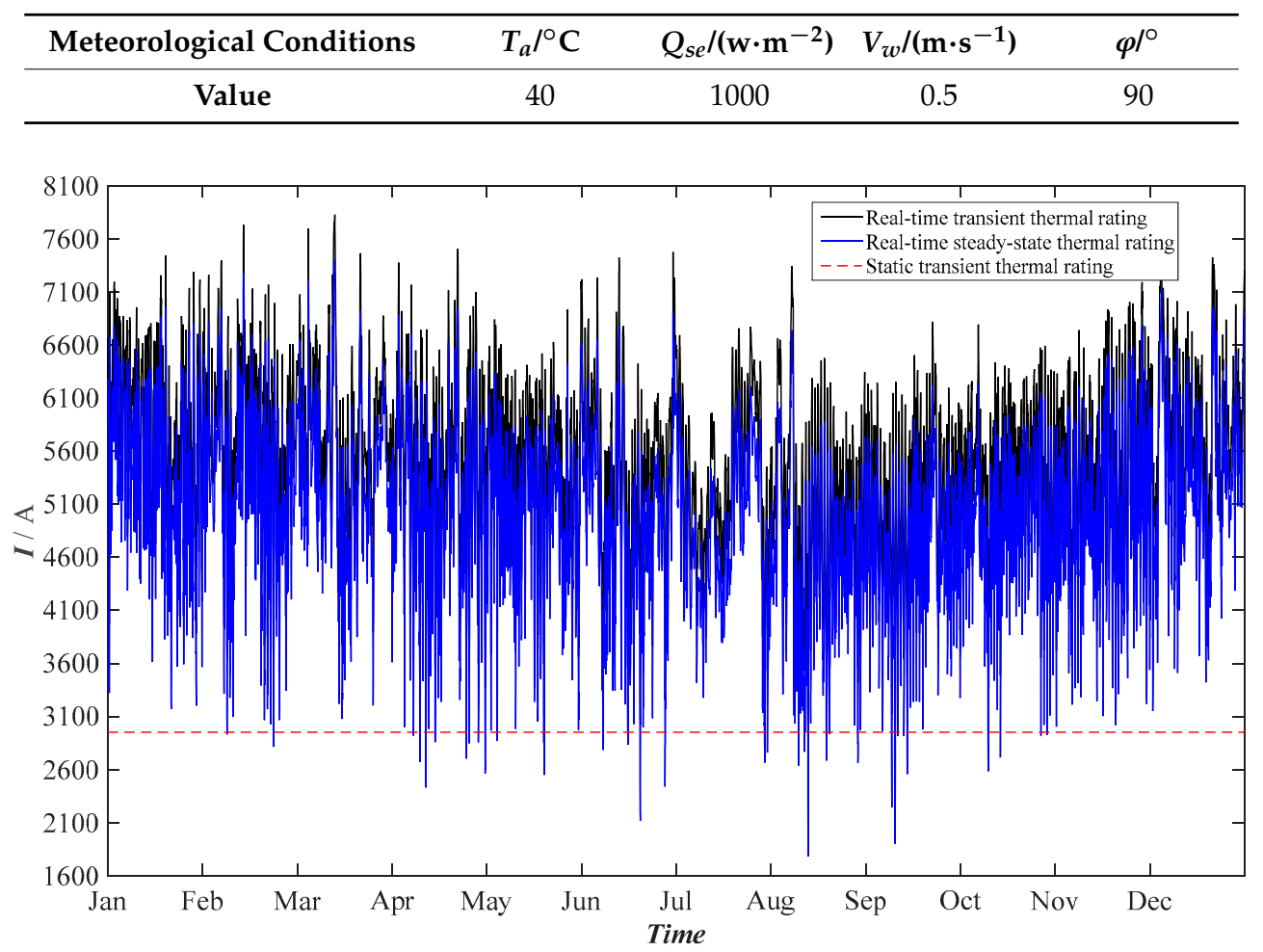

Figure 6. Comparison of thermal ratings under different conditions.

From the above figure, the values of static transient thermal rating, real-time steady-state, and transient thermal rating of the line in 2012 are $2952 \mathrm{~A}, 1782 \mathrm{~A}$ to $7402 \mathrm{~A}$, and $2824 \mathrm{~A}$ to $7828 \mathrm{~A}$, respectively. Compared the first two with the real-time transient thermal rating, the values decrease about $35.71 \%$ and $13.78 \%$ each. The result shows that static thermal rating provides a very conservative result which can ensure high safety of operation, but a severe waste of the capacity of the line. The real-time steady-state thermal rating can improve the capacities, but not lead to full utilization of the line. Only real-time transient thermal rating can unlock the hidden capacity and achieve the purpose of increasing the capacity of the line in a relatively short period of time with strong reliability.

\subsection{Influence of Different Variables upon Transient Thermal Rating}

Remaining time and initial temperature of the conductor are the two main factors that would affect the value of transient thermal rating of the transmission line. In this paper, the meteorological data of tower 1 of this line on 30 June 2012 at 12:00 is taken as an example to study the influence of these two factors upon the transmission line. Table 5 shows the specific meteorological data in that time. 
Table 5. Specific value of tower 1 in 30 June 2012 at 12:00.

\begin{tabular}{ccccc}
\hline Meteorological Conditions & $T_{a} /{ }^{\circ} \mathrm{C}$ & $Q_{s e} /\left(\mathbf{w} \cdot \mathbf{m}^{-2}\right)$ & $V_{w} /\left(\mathbf{m} \cdot \mathbf{s}^{-1}\right)$ & $\varphi^{\prime \circ}$ \\
\hline Value & 35.26 & 889.9 & 7.1 & 20 \\
\hline
\end{tabular}

\subsubsection{Influence of Remaining Time upon Transient Thermal Rating}

Remaining time is the time the transmission line takes to rise from the initial temperature to the maximum allowable operating temperature. It is the safety time limit of the line. The transmission line will be put into danger if the operating time exceeds the remaining time, such as loss of strength and clearance of the line. When the initial temperature of the conductor is $25{ }^{\circ} \mathrm{C}, 50{ }^{\circ} \mathrm{C}$, and $70{ }^{\circ} \mathrm{C}$, respectively, with all the meteorological conditions remaining the same, the relationship between the remaining time and transient thermal rating is shown in Figure 7 and Table 6.

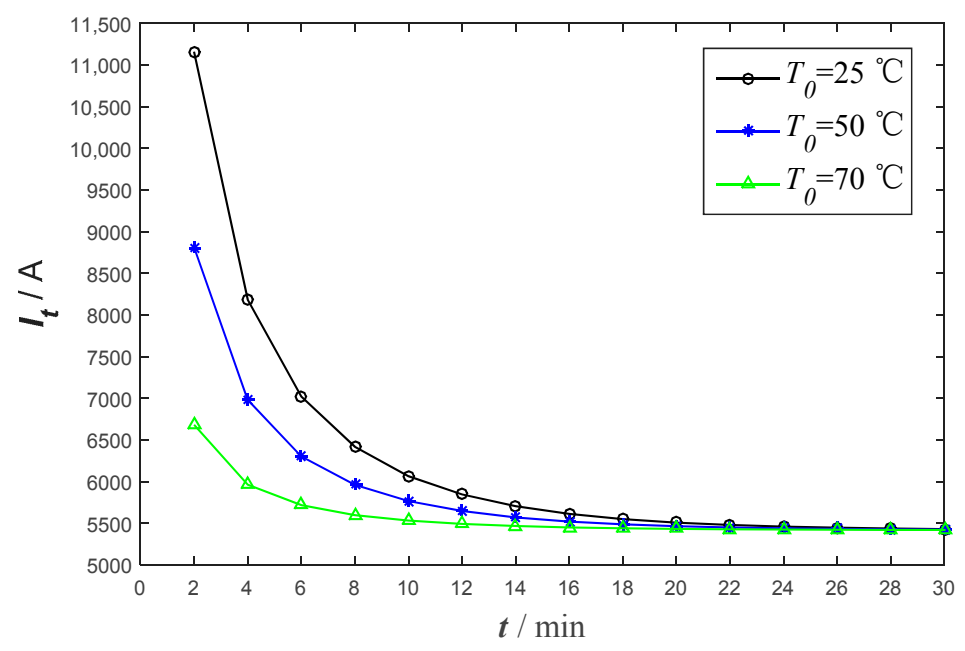

Figure 7. Relationship between remaining time and transient thermal rating under different initial temperatures.

Table 6. Specific value of remaining time and transient thermal rating under different initial temperatures.

\begin{tabular}{cccc}
\hline $\boldsymbol{t} / \mathbf{m i n}$ & $\boldsymbol{T}_{\mathbf{0}}=\mathbf{2 5}{ }^{\circ} \mathbf{C}$ & $\boldsymbol{T}_{\mathbf{0}}=\mathbf{5 0}{ }^{\circ} \mathrm{C}$ & $\boldsymbol{T}_{\mathbf{0}}=\mathbf{7 0}{ }^{\circ} \mathrm{C}$ \\
\hline 2 & $11,158.8 \mathrm{~A}$ & $8810.8 \mathrm{~A}$ & $6682 \mathrm{~A}$ \\
10 & $6065.2 \mathrm{~A}$ & $5766.4 \mathrm{~A}$ & $5532.8 \mathrm{~A}$ \\
30 & $5430.8 \mathrm{~A}$ & $5424 \mathrm{~A}$ & $5419.2 \mathrm{~A}$ \\
\hline
\end{tabular}

From the above figure and table, when $T_{0}=25{ }^{\circ} \mathrm{C}$, the values of transient thermal rating at $t=10 \mathrm{~min}$ and $t=30 \mathrm{~min}$ are reduced by $45.6 \%$ and $51.3 \%$, respectively, compared with when $t=2$ min. When $T_{0}=50{ }^{\circ} \mathrm{C}$, the values of transient thermal rating of $t=10 \mathrm{~min}$ and $t=30 \mathrm{~min}$ decreased by $34.6 \%$ and $38.4 \%$, respectively, compared with when $t=2 \mathrm{~min}$. When $T_{0}=70{ }^{\circ} \mathrm{C}$, the values of transient thermal rating at $t=10 \mathrm{~min}$ and $t=30 \mathrm{~min}$ are reduced by $17.2 \%$ and $18.9 \%$, respectively, compared with when $t=2$ min.

In general, one can conclude that the value of transient thermal rating is decreasing with the increment of remaining time when the initial temperature of the conductor is fixed, which would allow the operator to determine the amount of time a line could be held at that ampacity before risking the reliability. 


\subsubsection{Influence of Initial Temperature upon Transient Thermal Rating}

The initial temperature of an overhead transmission line is defined as the operating temperature at which it is already under stable operation at the present current, before a jump current is applied thereto. When the remaining time of the conductor is $15 \mathrm{~min}$ and $30 \mathrm{~min}$, the relationship between initial temperature and transient ampacities under different ambient meteorological conditions is studied, and the result is shown in Figure 8.

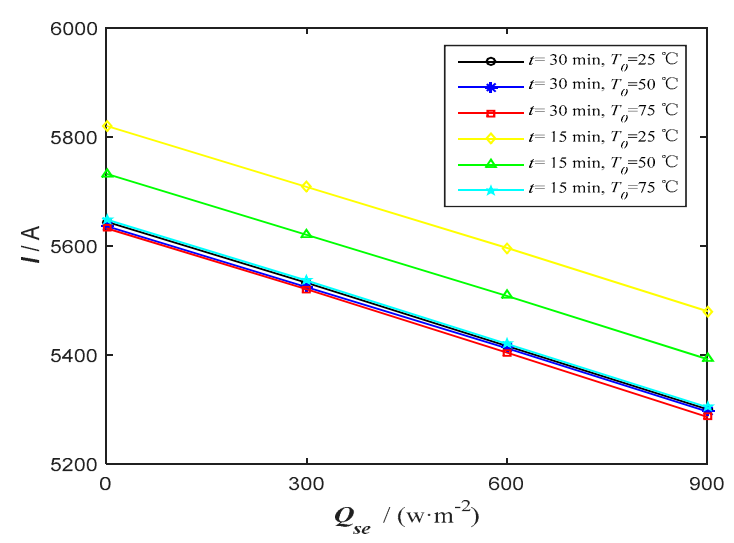

(a)

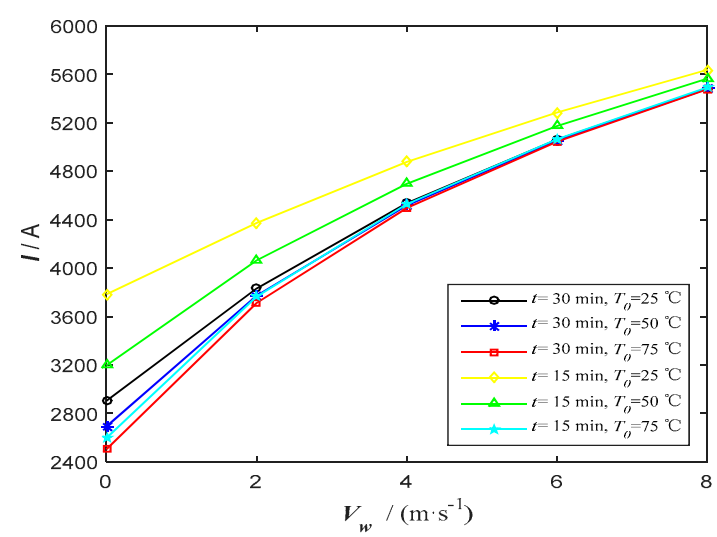

(c)

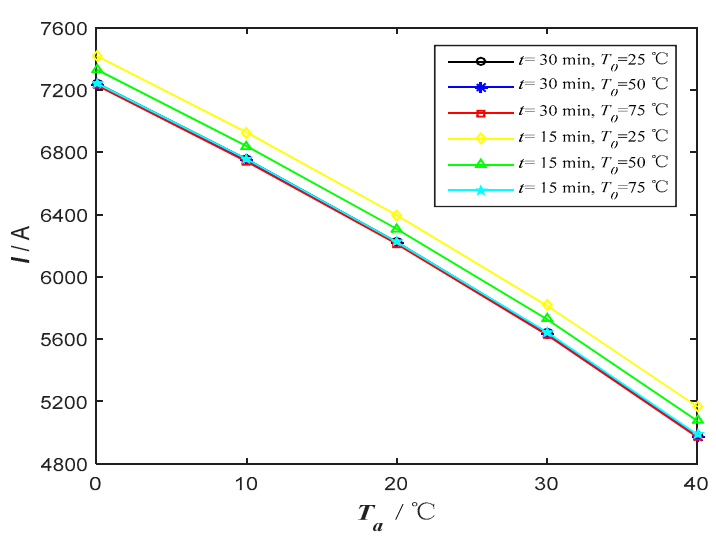

(b)

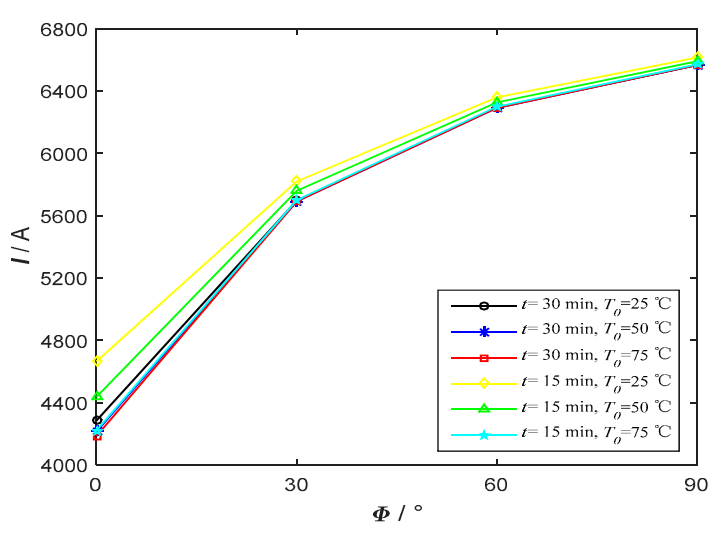

(d)

Figure 8. (a) Relationship between initial temperature and transient ampacities under different solar radiated heat intensity; (b) relationship between initial temperature and transient ampacities under different ambient temperature; (c) relationship between initial temperature and transient ampacities under different wind speed; (d) relationship between initial temperature and transient ampacities under different angle between wind and axis of conductor.

As can be seen from the above figure, different meteorological conditions have different influences upon transient ampacities. Transient ampacity will decrease with the increment of solar radiated heat intensity and ambient temperature. It also will increase with the increment of wind speed and angle between wind and axis of conductor. Moreover, the value of transient thermal rating is decreasing with the increment of initial temperature when the remaining time of the conductor is fixed. This is because when the initial temperature is higher, there is less room for temperature increment, and the following consequence is the ever-decreasing ampacity. It is noteworthy that when $t=30 \mathrm{~min}$, the curves of transient ampacity almost coincide, which means the impact of the initial temperature upon the transient ampacity is gradually reduced when remaining time is increasing. 


\section{Calculation and Analysis of Risk Level of Transmission Lines}

The risk level of an overhead transmission line is defined as the percentage of time the thermal rating can be expected to exceed the ampacity [22]. The steady-state and transient thermal rating of the line under real-time conditions at $t=10 \mathrm{~min}, t=20 \mathrm{~min}, t=30 \mathrm{~min}$, was calculated for the year 2012 with a time resolution of one hour. The calculating parameters are the same as in Table 3. After calculating the ampacities of whole towers of the line, the final ampacity was determined as the minimum value over all towers. The results are shown in Figure 9.

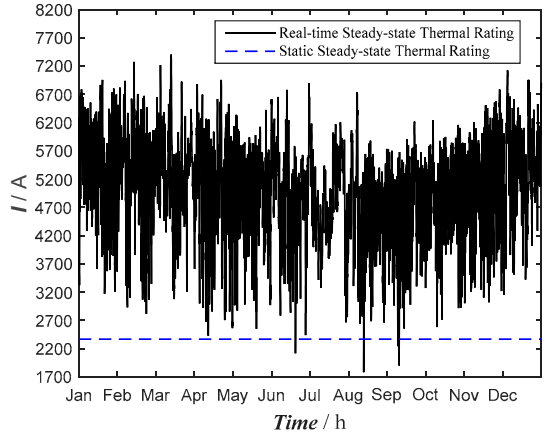

(a)

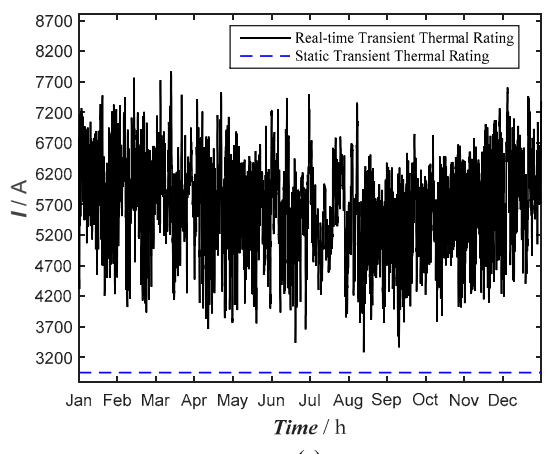

(c)

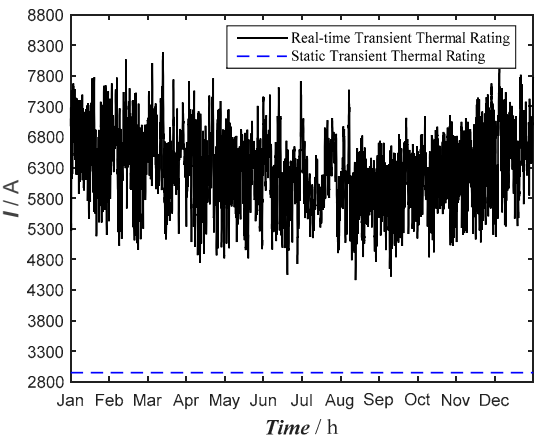

(b)

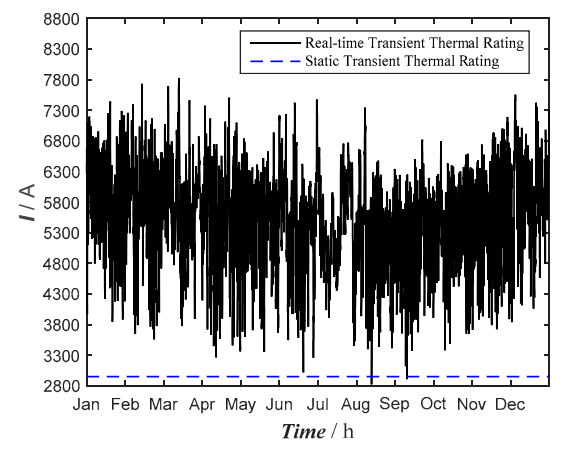

(d)

Figure 9. (a) Steady-state thermal rating of the line under real-time and static conditions in 2012;

(b) when $t=10 \mathrm{~min}$, transient thermal rating of the line under real-time and static conditions in 2012;

(c) when $t=20 \mathrm{~min}$, transient thermal rating of the line under real-time and static conditions in 2012;

(d) when $t=30 \mathrm{~min}$, transient thermal rating of the line under real-time and static conditions in 2012.

The values of steady-state and transient thermal rating of the line under real-time conditions at $t=10 \mathrm{~min}, t=20 \mathrm{~min}, t=30 \mathrm{~min}$, varies from $1781.7 \mathrm{~A}$ to $7402.4 \mathrm{~A}, 4464 \mathrm{~A}$ to $8188 \mathrm{~A}, 3284 \mathrm{~A}$ to $7872 \mathrm{~A}$, and $2848 \mathrm{~A}$ to $7828 \mathrm{~A}$, through the year. Under static conditions, the values of steady-state and transient thermal rating are $2368 \mathrm{~A}$ and $2952 \mathrm{~A}$, respectively. A statistical analysis by cumulative distribution function (CDF) and cumulative frequency distribution function (CFDF) of the calculated ampacity is performed to study the risk level of this line. Figure 10 shows the steady-state and transient $\mathrm{CDF}$ of the thermal rating, and Table 7 presents the specific values of thermal ratings when risk level varies from 0 to $5 \%$ in an increment of $1 \%$.

Table 7. Specific values of thermal ratings when risk level varies from 0 to $5 \%$.

\begin{tabular}{ccccccc}
\hline Risk Level & $\mathbf{0 \%}$ & $\mathbf{1 \%}$ & $\mathbf{2 \%}$ & $\mathbf{3 \%}$ & $\mathbf{4 \%}$ & $\mathbf{5 \%}$ \\
\hline Steady-state rating/A & 1781.7 & 2932.3 & 3147.2 & 3307.8 & 3444.9 & 3537.2 \\
Transient rating at $t=10 \mathrm{~min} / \mathrm{A}$ & 4464 & 4963.9 & 5082.7 & 5171.1 & 5244.9 & 5297.5 \\
Transient rating at $t=20 \mathrm{~min} / \mathrm{A}$ & 3284 & 3987.9 & 4152.3 & 4258.3 & 4352.2 & 4427.3 \\
Transient rating at $t=30 \mathrm{~min} / \mathrm{A}$ & 2824 & 3632.6 & 3818.6 & 3952.4 & 4063.2 & 4143.4 \\
\hline
\end{tabular}




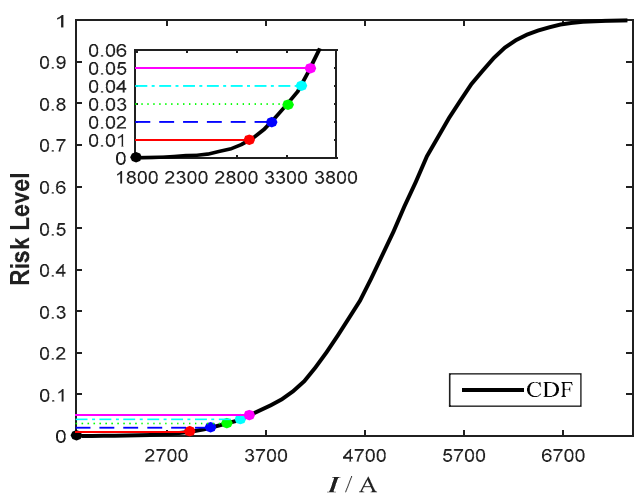

(a)

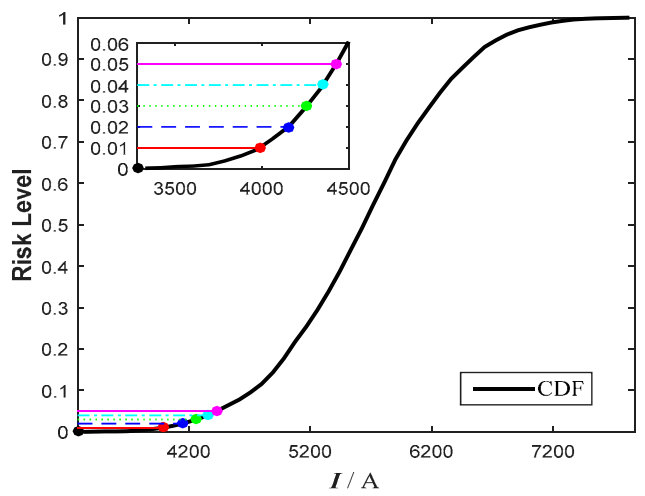

(c)

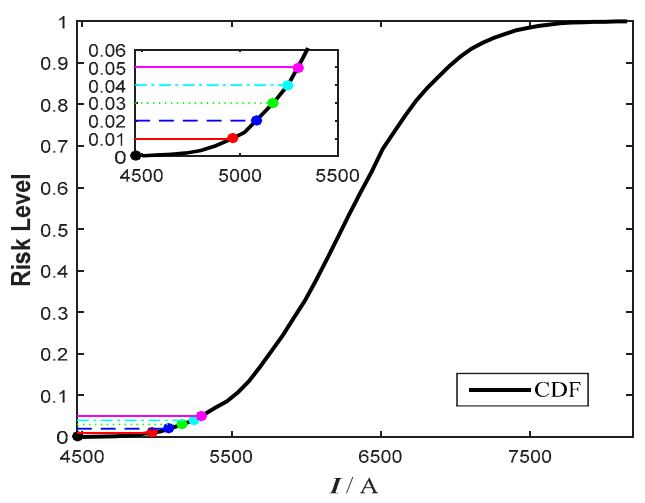

(b)

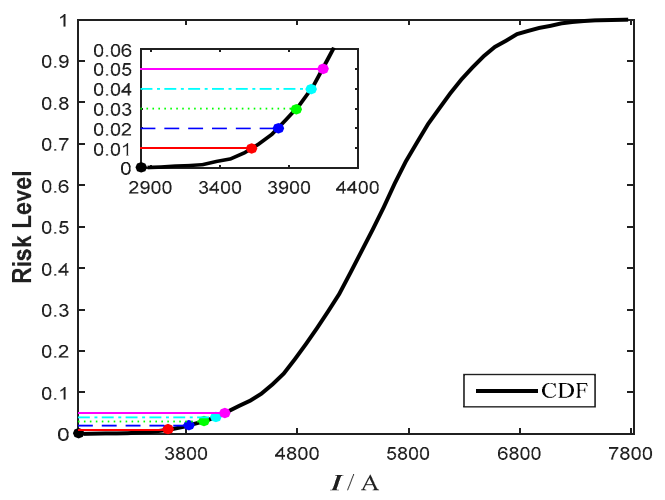

(d)

Figure 10. (a) Cumulative distribution function (CDF) of steady-state thermal rating; (b) CDF of transient thermal rating at $t=10 \mathrm{~min}$; (c) CDF of transient thermal rating at $t=20 \mathrm{~min}$; (d) CDF of transient thermal rating at $t=30 \mathrm{~min}$.

From the above figure and table, one can conclude that with smaller remaining time, the ampacities are larger; with larger ampacities, the risk of thermal overload is greater. The choice of risk level has significant impact on the value of ampacity. For example, the difference between steady-state and transient ratings at $t=10 \mathrm{~min}, t=20 \mathrm{~min}, t=30 \mathrm{~min}$, using risk level $0 \%$ and $5 \%$ are about 1755.5 A, 833.5 A, 1143.3 A, and 1319.4 A respectively, corresponding to a $98.53 \%, 18.67 \%, 34.81 \%$, and $46.72 \%$ increment of the rating values. Figure 11 shows the steady-state and transient CFDF of the thermal ratings.

The corresponding risk levels of steady-state and transient thermal ratings at $t=10 \mathrm{~min}, 20 \mathrm{~min}$, $30 \mathrm{~min}$, under static conditions in the CFDF are only $0.13 \%, 0 \%, 0 \%$, and $0.12 \%$, respectively. The risk is very low under these conservative results, for most of the time, real-time thermal rating allows more power to be transmitted through the line compared to static rating, but static rating does not represent the worst situation. During the summer time, a few cases indicate that static thermal rating turns out to be an overestimation of the line capacity, the risk of overload cannot be eliminated completely.

At present, there is no relative standard for setting the risk level. The decisions should made by the operators according to the parameters and specific external environment conditions of the line. The most conservative thermal rating would be determined using $0 \%$ risk level. However, $2-5 \%$ risk level are widely accepted, which is considered conservative enough. 

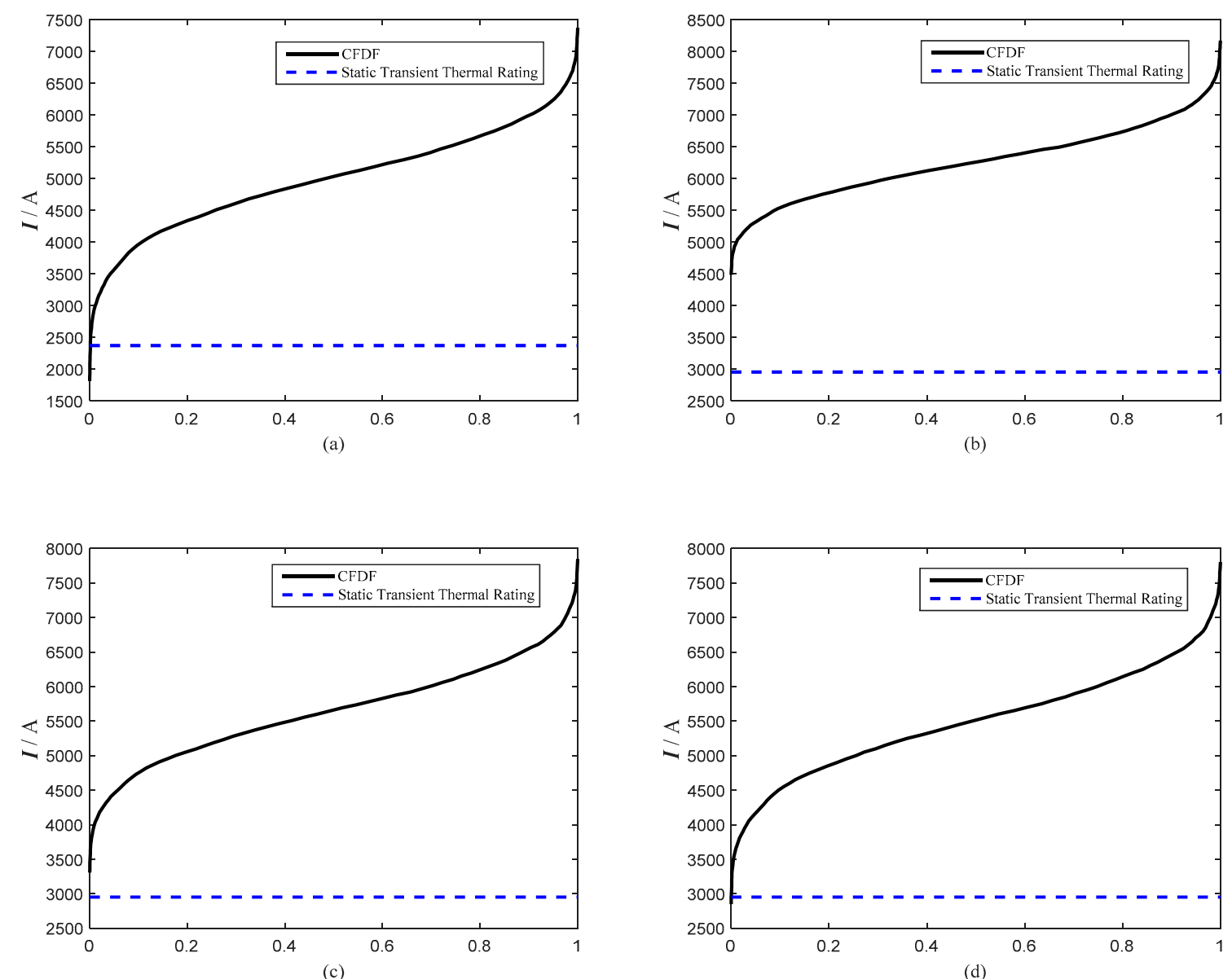

Figure 11. (a) Cumulative frequency distribution function (CFDF) of steady-state thermal rating; (b) CFDF of transient thermal rating at $t=10 \mathrm{~min}$; (c) CFDF of transient thermal rating at $t=20 \mathrm{~min}$; (d) CFDF of transient thermal rating at $t=30 \mathrm{~min}$.

\section{Conclusions}

This paper presents the transient thermal balance of overhead transmission lines. The method of transient thermal rating of overhead transmission lines is introduced. A $500 \mathrm{kV}$ quad bundle transmission line in Zhejiang Province, China, is selected to study the transient thermal rating in the whole year and the temperature increment at every time step can be tracked by this method. When the temperature rises, approaching the maximum allowable temperature, the temperature increment becomes slower, due to that the heat dissipated by the conductor continues to approach the heat absorbed by the conductor, and the residual heat that makes the temperature rise is continuously decreasing.

A comparison among the static, real-time steady-state, and transient thermal ratings is made. The result shows that real-time transient thermal rating can unlock the hidden capacity and achieve the purpose of increasing the capacity of the line in a relatively short period of time.

The influence of remaining time and initial temperature upon transient thermal rating is studied. The result shows that with the increment of remaining time and initial temperature, the value of transient thermal rating is continuously decreasing.

Through the CDF and CFDF of the steady-state and transient thermal ratings, the risk level of transmission line is studied. The result shows that with smaller remaining time, the ampacities are larger; and with larger ampacities, the risk of thermal overload is greater. The choice of risk level has significant impact on the value of ampacity. Under the static conditions, the thermal risk is quite low, but the capacity of the line is highly limited. 
Author Contributions: Both authors contributed equally to all the sections of this work.

Acknowledgments: The authors would like to acknowledge the support from State Key Laboratory of Power Transmission Equipment \& System Security and New Technology, Chongqing University.

Conflicts of Interest: The authors declare no conflict of interest.

\section{References}

1. Yang, Y.; Harley, R.G.; Divan, D.; Habetler, T.G. Thermal modeling and real time overload capacity prediction of overhead power lines. In Proceedings of the IEEE International Symposium on Diagnostics for Electric Machines, Power Electronics and Drives, Cargese, France, 31 August-3 September 2009; pp. 1-7.

2. Denholm, P.; Hand, M. Grid flexibility and storage required to achieve very high penetration of variable renewable electricity. Energy Policy 2013, 39, 1817-1830. [CrossRef]

3. Patowary, P.; Goyal, N.K. Dynamic thermal rating and allowable operating time under transient conditions. In Proceedings of the Power Systems Conference, Guwahati, India, 18-20 December 2014; pp. 1-6.

4. Jorge, R.S.; Hertwich, E.G. Environmental evaluation of power transmission in Norway. Appl. Energy 2013, 101, 513-520. [CrossRef]

5. Arya, L.D.; Choube, S.C.; Shrivastava, M.; Kothari, D.P. Loadability margin enhancement using co-ordinated aggregation based particle swarm optimization (CAPSO). Int. J. Electr. Power Energy Syst. 2010, 32, 975-984. [CrossRef]

6. Othman, M.M.; Musirin, I. A novel approach to determine transmission reliability margin using parametric bootstrap technique. Int. J. Electr. Power Energy Syst. 2011, 33, 1666-1674. [CrossRef]

7. Andrew, N. Not in our backyard!-A controversial electricity transmission line and charges of spying zap the reputation of Alberta's energy regulator. Can. Bus. 2007, 80, 77-83.

8. Douglass, D.; Edris, A.A. Maximize use of existing route. Transm. Distrib. World 2002, 3, $22-27$.

9. Shaker, H.; Zareipour, H.; Fotuhi-Firuzabad, M. Reliability modeling of dynamic thermal rating. IEEE Trans. Power Deliv. 2013, 28, 1600-1609. [CrossRef]

10. Bracale, A.; Andreotti, A.; Carpinelli, G.; Martinis, U.D. Probabilistic Index for Increasing Hourly Transmission Line Ratings. Int. J. Emerg. Electr. Power Syst. 2007, 8. [CrossRef]

11. Hall, J.F.; Deb, A.K. Prediction of overhead transmission line ampacity by stochastic and deterministic models. IEEE Trans. Power Deliv. 1988, 3, 789-800. [CrossRef]

12. Maksić, M.; Kosec, G.; Djurica, V.; Souvent, A.; Trobec, R. Dynamic thermal rating of power lines in raining conditions-Model and measurements. In Proceedings of the Power and Energy Society General Meeting (PESGM), Boston, MA, USA, 17-21 July 2016.

13. Arroyo, A.; Castro, P.; Martinez, R.; Manana, M.; Madrazo, A.; Lecuna, R.; Gonzalez, A. Comparison between IEEE and CIGRE thermal behaviour standards and measured temperature on a 132-kV overhead power line. Energies 2015, 8, 13660-13671. [CrossRef]

14. IEEE. IEEE Std 738-2012: IEEE Standard for Calculation the Current-Temperature Relationship of Bare Overhead Conductors; IEEE Standard Association: Washington, DC, USA, 2013.

15. International Council on Large Electric Systems (CIGRE). Guide for Thermal Rating Calculation of Overhead Lines; Technical Brochure 601; CIGRE: Paris, France, 2014.

16. Musavi, M.; Chamberlain, D.; Li, Q. Overhead conductor dynamic thermal rating measurement and prediction. In Proceedings of the Smart Measurements for Future Grids (SMFG), Bologna, Italy, 14-16 November 2011; pp. 135-138.

17. Teh, J.; Cotton, I. Risk assessment of dynamic thermal rating system. In Proceedings of the Resilience of Transmission and Distribution Networks (RTDN), Birmingham, UK, 22-24 September 2015; pp. 1-6.

18. Ringelband, T.; Schäfer, P.; Moser, A. Probabilistic ampacity forecasting for overhead lines using weather forecast ensembles. Electr. Eng. 2013, 95, 99-107. [CrossRef]

19. Zhan, J.; Chung, C.Y.; Demeter, E. Time series modelling for dynamic thermal rating of overhead lines. In Proceedings of the Power \& Energy Society General Meeting, Chicago, IL, USA, 16-20 July 2017; pp. 1-10.

20. Greenwood, D.M.; Ingram, G.L.; Taylor, P.C. Applying wind simulations for planning and operation of real-time thermal ratings. IEEE Trans. Smart Grid 2017, 8, 537-547. [CrossRef] 
21. Rahman, S.A.; Kopsidas, K. Modelling of convective cooling on conductor thermal rating methods. In Proceedings of the PowerTech, Manchester, UK, 18-22 June 2017; pp. 1-6.

22. Heckenbergerová, J.; Musilek, P.; Filimonenkov, K. Quantification of gains and risks of static thermal rating based on typical meteorological year. Int. J. Electr. Power Energy Syst. 2013, 44, 227-235. [CrossRef] 